\title{
PERBAIKAN TATA LETAK GUDANG PRODUK JADI DENGAN METODE DEDICATED STORAGE DIGUDANG PT. YYZ
}

\author{
Saddam Husin \\ e-mail : saddam-husin@student.umaha.ac.id \\ Teknik Industri, Fakultas Teknik \\ Universitas Maarif Hasyim Latif, Sidoarjo, Indonesia
}

\begin{abstract}
ABSTRAK
PT. YYZ sebagai perusahaan distribusi dimana perusahaan ini akan menjalankan bisnisnya dengan cara mendistribusikan semua produk yang ada dalam gudang ke pelangganya, oleh karena itu PT.YYZ memerlukan gudang yang baik agar dapat mendistribusikan produknya namun sampai saat ini PT. YYZ masih mengalami sedikit permasalahan di sisi gudangnya dimana penyimpanan produk berdasarkan ruang yang kosong. Oleh karena itu perlu dilakukan perubahan penempatan barang agar lebih baik dalam sisi peletakan. Dengan metode Dedicated Storege ini akan merubah tata letak barang dan memberikan grouping pada setiap produk serta meletakkan produk sesuai dengan aktivitasnya sehingga jarak tempuh barang tersebut lebih pendek. Dari hasil penelitian yang di lakukan dapat di peroleh jarak tempuh eksisting 420,424m sedangkan jarak tempuh usulan 290,697m sehingga terdapat selisih prosentase $30,86 \%$.
\end{abstract}

Kata kunci: dedicated storage, gudang, grouping, jarak tempuh, penyimpanan, tata letak gudang,

\section{PENDAHULUAN}

PT. YYZ merupakan perusahaan yang bergerak di bidang distribusi dimana perusahaan ini menjalankan bisnisnya dengan menyalurkan semua produk sampai pelangganya, oleh karena itu agar perusahaan ini mampu melayani pelangganya dengan baik maka di butuhkanya gudang yang baik dimana gudang saat ini memiliki luas $4,372 \mathrm{~m}^{2}$ dengan kapasitas penyimpanan 2,600 pallet namun dalam penyimpananya masih menggunakan metode random penyimpanan ini menyebabkan tidak adanya posisi penempatan yang tetap sehingga setiap produk bisa di temptakan dimana saja, oleh karena itu menyebabkan pencarian produk dan jarak tempuh produk ke titit I/O jadi semakin besar.

Penelitian dari (Retnowati \& Fudhla, n.d.) dalam penelitianya berjudul Re-layout Fasilitas Produksi Industry Sheet Metal Working berbasis Job Shop Dengan Pendekatan Linier Mix Integer Programing yang mendapatatkan hasil penelitian yakni dapat mereduksi atau memperkecil total beban dari pergerakan entitas (waktu dan biaya Material Handling) mencapai 38,5\% di bandingkan dengan tata letak pada kondisi eksisting atau kondisi awal.

Dalam penelitian ini metode dediated storage berfungsi mengatasi masalah penyimpanan dimana posisi produk akan memiliki posisi yang tetap sehingga di harapkan dapat memperpendek jarak tempuh produk yang di simpan.

\section{METODE PENELITIAN}

\section{Tahapan Penelitian}

Dalam penelitian ini terdapat beberapa tahapan yang harus dilakukan agar dapat mencapai hasil yang di inginkan oleh peneliti :

1. Space Requirement

Space Requirement adalah kebutuhan tempat atau ruang dari setiap produk yang akan di simpan dalam gudang, dengan adanya Space Requirement akan memudahkan dalam pembagian tempat dan memberitahu seberapa banyak pallet yang di butuhkan untuk menyimpan barang. Dengan adanya ini bisa di jadikan patokan untuk mengalokasikan luas gudang atau banyaknya pallet yang akan di gunakan agar pemakaian pallet dan luas gudang jadi lebih efisien dan teratur.

2. Perhitungan Troughput

Troughput merupakan aktivitas dari barang yang di simpan di dalam gudang, dengan adanya Troughput akan memudahkan dalam menghitung aktivitas barang jadi dapat mengklasifikasikan mana saja barang yang slow moving dan fast moving. Dengan troughput ini sebagai acuan atau dasar peletakan awal barang yang akan di simpan dalam gudang. 
3. Perbandingan Troughput dan Space

Requirement

Perbandingan antara Troughput dan Space requirement bertujuan untuk membagi produk atau barang yang di simpan menjadi beberapa bagian yakni aktivitas tinggi , rendah dan sedang. Dengan adanya pembagian ini akan lebih muda dalam membuat rencanganan tata letak yang ada dalam gudang atas dasar perbandingan Troughput dan Space requirement disamping itu akan memudahkan dalam mengelompokan barang sesuai dengan spesifikasinya.

4. Perhitungan jarak Material Handling ke I/O. Perhitungan jarak material handling ini bertujuan agar mengetahui seberapa jauh jarak material terhadapa titik I/O sehingga dengan adanya ini akan lebih muda membandingkan antara jarak material handling awal dengan jarak material handling usulan. Perhitungan ini memperhitungkan antara jarak produk dari tempat penyimpanan sampai dengan titik I/O.

5. Perhitungan jarak tempuh eksisting

Jarak tempuh ini memperhitungkan jarak tempuh material handling dari titik penyimpanan atau pallet sampai ke titik I/O dimana jarak ini adalah jarak usulan.

6. Perbandingan jarak tempuh

Perbaikan atau usulan perhitungan ini hanya membandingkan antara jarak tempuh eksisting dan jarak usulan, dalam perhitungan ini bertujuan mengetahui hasil yang telah di teliti apakah hasilnya semakin pendek jarak tempuh material handling-nya atau semakin jauh.

\section{Metode Penyimpanan}

Menurut (Hadiguna \& Setiawan, 2008) penyimpanan gudang memiliki beberapa macam alternatif dalam menyimpan barang jadi di dalam gudang yakni :

1. Metode Dedicated Storage

Metode ini menekankan kepada spesfikasi penyimanan barang, dimana barang yang disimpan memiliki tempat yang tetap sehingga memudahkan dalam mencarinya dan dalam peletakan barang yang di simpan dalam gudang juga di dasarkan kepada aktivitas barang tersebut. Jika produk atau barang tersebut memiliki aktivitas tinggi atau fast moving maka peletakan barang tersebut akan semakin dekat dengan titik I/O. begitu juga sebaliknya jika barang tersebut slow moving maka peletakan barang tersebut akan semakin jauh dengan titik I/O.

2. Metode Random Storage

Metode ini memiliki kelebihan Utilisasi yang baik di bandingkan dengan metode Dedicated Storage dimana metode tersebut membutuhkan tempat penyimpanan yang banyak namun metode ini tidak memiliki tempat yang tetap dalam menyimpan barangnya sehingga semua produk dapat mencampur jadi satu sehingga pencarian barangnya akan semakin sulit yang mengakibatkan waktu pencarian juga semakin lama.

3. Metode Classed Based Storage

Metode ini adalah gabungan 2 metode antara Dedicated Storage dan Random storage. Metode ini akan di jadikan menjadi beberap kelas dimana jika metode ini di bagi atas dasar produk maka akan menjadi dedicate Storage namun jika metode ini di jadikan satu maka akan menjadi Metode Random Storage.

4. Metode Shared Storage Location

Metode ini lebih berfungsi kepada penanganan masalah yang ada di metode Dedicated Storage dan metode Random Storage dengan memahami dan memanfaatkan hasil dari perbedaan waktu lama penyimpanan barang pada pallet yang di sempan di gudang.

\section{HASIL DAN PEMBAHASAN}

\section{Tata Letak Gudang Awal}

PT. YYZ merupakan perusahaan distribusi yang mengharuskan memiliki gudang yang baik dan memadai, gudang yang di miliki PT. Bor wita Citra Prima memiliki luas total $4,374 \mathrm{~m}^{2}$ dengan panjang $54 \mathrm{~m}^{2}$ dan lebar $81 \mathrm{~m}^{2}$. Sebelum produk jadi di simpan di gudang kebanyakan produk yang berasal dari principle banyak menggunakan karton sehingga lebih muda dalam penyimpanan.

Di dalam gudang memiliki beberapa alat untuk mengambil barang simpanan yakni forklift dengan adanya ini akan memudahkan dalam menyimpan dan mengambil barang yang ada di atas atau jauh dari jangkauan operator gudang. Berikut layout gudang exixting : 


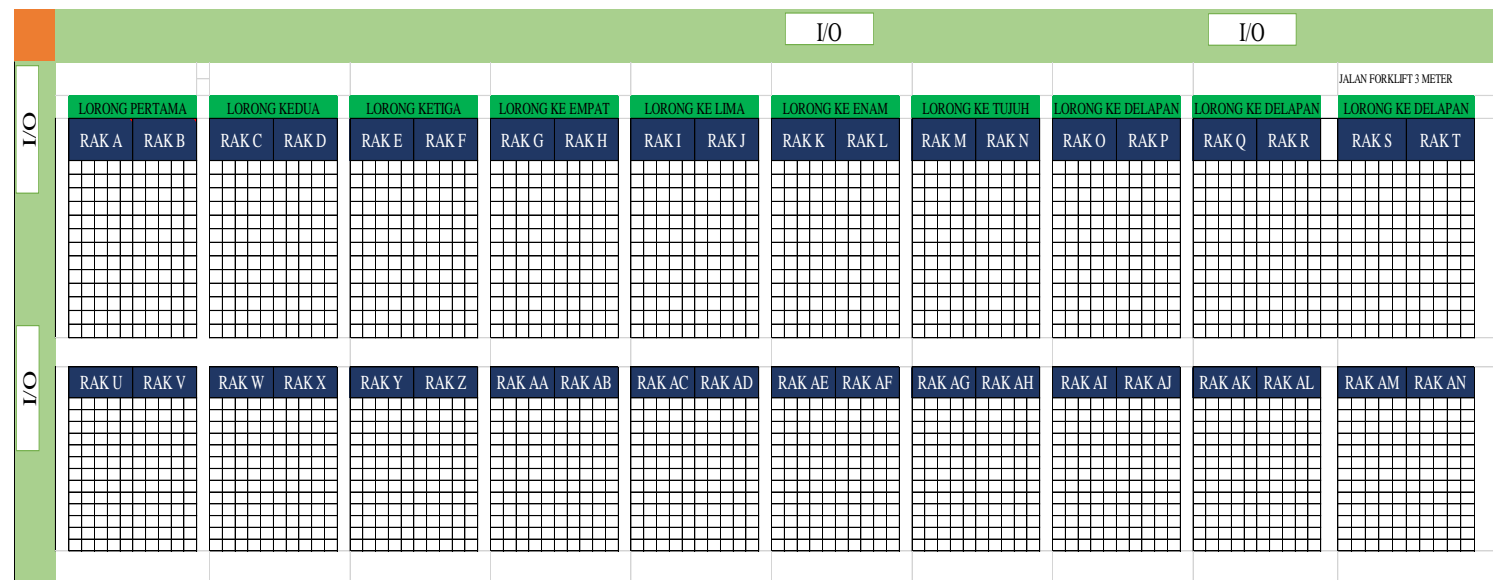

Gambar 1. Layout gudang

\section{Pengolahan Data}

Semua data yang sudah di peroleh dari studi lapangan atau studi pustaka akan di lakukan pengolahan data selanjutnya yakni dengan metode dedicated storage dimana terdapat beberapa langkah yang harus di lakukan dalam melakukan atau menjalankan metode dedicated storage ini.

\section{Space Requirement}

Metode Dedicated Storage memiliki beberapa bagian di antaranya yakni Space Requirement dimana bagian ini menjelaskan tentang pembagian tempat penyimpanan atau spesifik tempat untuk 1 jenis barang dalam lokasi penyimpanan atau gudang.

\section{Perhitungan Throughput}

Troughput merupakan cara untuk mengukur suatu aktivitas dalam gudang yakni bisa sebagai penyimpanan atau penjualan dalam periode tertentu, sehingga dalam perhitungannya akan didasarkan pada pengukuran penerimaan aktivitas dan pengiriman atau penjualan dalam gudang produk jadi.

Dalam aktivitasnya di dalam gudang dalam mengoperasionalkan pengiriman dan penerimaan barang dengan menggunakan forklift, dalam setiap operasionalnya forklift hanya mampu membawa 1 pallet setiap kali beraktivitas, sehingga dalam menentukan banyaknya produk yang dapat di angkut.

Tabel 1. Kebutuhan Ruang setiap jenis produk P\&G

\begin{tabular}{|l|l|l|l|c|l|l|l|l|}
\hline No & Kode Barang & Nama Barang & $\begin{array}{l}\text { Pene } \\
\text { rima } \\
\text { an } \\
\text { per } \\
\text { crt }\end{array}$ & Rasio & $\begin{array}{l}\text { Rata } \\
\text { Rata } \\
\text { Peneri } \\
\text { amaan } \\
\text { Per } \\
\text { Pcs }\end{array}$ & $\begin{array}{l}\text { Kapas } \\
\text { itas }\end{array}$ & $\begin{array}{l}\text { Space } \\
\text { requireme } \\
\text { nt Teoritis }\end{array}$ & $\begin{array}{l}\text { Space } \\
\text { requir } \\
\text { ement } \\
\text { Eksisti } \\
\text { ng }\end{array}$ \\
\hline 1 & $01 / 316027110 \mathrm{E}$ & Ap Car Aqua RF 7ml (6) & 60.0 & 6 & 72.0 & 510 & 0.14 & 1 \\
\hline 2 & $01 / 316027112 \mathrm{D}$ & Ap Car Aqua ST 7ml (4) & 52.0 & 4 & 41.6 & 340 & 0.12 & 1 \\
\hline 3 & $01 / 316027110 \mathrm{~L}$ & Ap Car ATBC RF 7.5ml (6) & 72.0 & 6 & 86.4 & 510 & 0.17 & 1 \\
\hline 4 & $01 / 316027112 \mathrm{~K}$ & Ap Car ATBC ST 7.5ml (6) & 24.0 & 4 & 19.2 & 340 & 0.06 & 1 \\
\hline 5 & $01 / 316027110 \mathrm{H}$ & Ap Car F\&cool RF 7ml (6) & 114.0 & 6 & 136.8 & 510 & 0.27 & 1 \\
\hline
\end{tabular}


Tabel 2. Kebutuhan Ruang setiap jenis produk Arnot

\begin{tabular}{|c|l|l|c|c|c|c|c|c|}
\hline No & Kode & Nama Barang & $\begin{array}{l}\text { Peneri } \\
\text { maan }\end{array}$ & Rasio & $\begin{array}{l}\text { Rata Rata } \\
\text { Penerima } \\
\text { an per } \\
\text { Pcs }\end{array}$ & $\begin{array}{l}\text { Kapasi } \\
\text { tas }\end{array}$ & $\begin{array}{l}\text { Space } \\
\text { requirem } \\
\text { ent } \\
\text { Teoritis }\end{array}$ & $\begin{array}{l}\text { Space } \\
\text { requirement } \\
\text { Eksisting }\end{array}$ \\
\hline 1 & $20 / 020200601 \mathrm{H}$ & $\begin{array}{l}\text { As - Good Time } \\
\text { Assorted Bsr } \\
1 / 12 / 277 g\end{array}$ & 3726 & 12 & 8,942 & 1,020 & 9 & 9 \\
\hline 2 & AAABC & $\begin{array}{l}\text { As- Good Time } \\
\text { Assorted KCL } \\
1 / 12 / 149 \mathrm{~g}\end{array}$ & 5834 & 12 & 14,002 & 1,020 & 14 & 14 \\
\hline 3 & $20 / 020200101 \mathrm{I}$ & $\begin{array}{l}\text { As - Venezia } \\
\text { Assorted Tin BSR } \\
1 / 6 / 565 \mathrm{~g}\end{array}$ & 1971 & 6 & 2,365 & 510 & 5 & 5 \\
\hline 4 & $20 / 010100103 \mathrm{~V}$ & $\begin{array}{l}\text { As - Venezia } \\
\text { Assorted TIN } \\
\text { KCL } 1 / 12 / 250 \mathrm{~g}\end{array}$ & 1988 & 12 & 4,771 & 1,020 & 5 & 5 \\
\hline 5 & $20 / 010100103 \mathrm{~W}$ & $\begin{array}{l}\text { Good Time } \\
\text { Classic } 1 / 48 / 72 \mathrm{~g}\end{array}$ & 385 & 48 & 3,696 & 4,080 & 1 & 1 \\
\hline
\end{tabular}

Tabel 3. Perhitungan Troughput setiap produk P\&G

\begin{tabular}{|r|l|c|c|c|c|c|}
\hline No & Nama Barang & $\begin{array}{l}\text { Rata Rata } \\
\text { Penerimaan } \\
\text { per pcs }\end{array}$ & $\begin{array}{l}\text { Rata Rata } \\
\text { Penjualan } \\
\text { Per pcs }\end{array}$ & Rasio & $\begin{array}{l}\text { Kapasitas } \\
\text { Angkut }\end{array}$ & Aktivitas \\
\hline 1 & Ap Car Aqua RF 7ml (6) & 72 & 121 & 6 & 120 & 2 \\
\hline 2 & Ap Car Aqua ST 7ml (4) & 42 & 106 & 4 & 80 & 2 \\
\hline 3 & Ap Car Aqua RF 7.5ml (6) & 86 & 46 & 6 & 120 & 1 \\
\hline 4 & Ap Car Aqua ST 7.5ml (4) & 19 & 42 & 4 & 80 & 1 \\
\hline 5 & Ap Car F\&Cool RF 7ml (6) & 137 & 78 & 6 & 120 & 2 \\
\hline
\end{tabular}

Tabel 4. Perhitungan Troughput setiap produk Arnot

\begin{tabular}{|r|l|c|c|c|c|}
\hline No & NamaBarang & $\begin{array}{l}\text { Penerimaan } \\
\text { per pcs }\end{array}$ & $\begin{array}{l}\text { Penjualan } \\
\text { per Pcs }\end{array}$ & Kapasitas & Aktivitas \\
\hline & $\begin{array}{l}\text { AS-GOOD TIME ASSORTED BSR } \\
1 / 12 / 277 g-M G A 02\end{array}$ & 44,712 & 4,882 & 1,020 & 49 \\
\hline & $\begin{array}{l}\text { AS-GOOD TIME ASSORTED KCL } \\
1 / 12 / 149 g-M G A 01\end{array}$ & 14,002 & 7,225 & 1,020 & 21 \\
\hline 3 & $\begin{array}{l}\text { AS-VENEZIA ASSORTED TIN BSR } \\
\text { 1/6/565g-BUV02 }\end{array}$ & 2,365 & 1,123 & 510 & 7 \\
\hline & $\begin{array}{l}\text { AS-VENEZIA ASSORTED TIN KCL } \\
\text { 1/12/250g-BUV01 }\end{array}$ & 4,771 & 2,592 & 1,020 & 7 \\
\hline 5 & GOOD TIME CLASSIC 1/48/72g-MGC93 & 3,696 & 1,980 & 4,080 & 1 \\
\hline
\end{tabular}

Tabel 5. Perbandingan antara Throughput dan Space Requirement P\&G

\begin{tabular}{|r|l|l|c|c|c|}
\hline No & Kode & Nama Barang & Troughput & $\begin{array}{c}\text { Space } \\
\text { Requirement }\end{array}$ & T/S \\
\hline 1 & $01 / 265522101 \mathrm{D}$ & Formula 44 2x5ml @12'S(20 box) & 36 & 1 & 35.9 \\
\hline 2 & $01 / 326127203 \mathrm{R}$ & Downy daring RF 800ml(8) & 20 & 1 & 20.1 \\
\hline 3 & $01 / 326127202 \mathrm{~L}$ & Downy Mystique BTL 370ml(20) & 32 & 2 & 16.1 \\
\hline 4 & $01 / 326127303 \mathrm{Q}$ & Downy Passion RF 800ml(8) & 22 & 2 & 11.0 \\
\hline 5 & $01 / 326127402 \mathrm{R}$ & Downy Mistique 20ml(30 STR) & 214 & 22 & 9.7 \\
\hline
\end{tabular}


Saddam Husin/ JISO, Vol. 3. No.1, Juni 2020,

Tabel 6. Perbandingan antara Throughput dan Space Requirement Arnot

\begin{tabular}{|r|l|l|c|c|c|}
\hline No & Kode Barang & Nama Barang & Troughput & $\begin{array}{l}\text { Space } \\
\text { Requirement }\end{array}$ & T/S \\
\hline 1 & $20 / 010100127 \mathrm{G}$ & $\begin{array}{l}\text { AS-GOOD TIME ASSORTED BSR } \\
1 / 12 / 277 g-M G A 02\end{array}$ & 49 & 9 & 6 \\
\hline 2 & $20 / 010100149 \mathrm{G}$ & $\begin{array}{l}\text { AS-GOOD TIME ASSORTED KCL } \\
1 / 12 / 149 g-M G A 01\end{array}$ & 21 & 14 & 2 \\
\hline 3 & $20 / 020500156 \mathrm{~B}$ & $\begin{array}{l}\text { AS-VENEZIA ASSORTED TIN BSR } \\
1 / 6 / 565 g-B U V 02\end{array}$ & 7 & 5 & 1 \\
\hline 4 & $20 / 020500125 \mathrm{~A}$ & $\begin{array}{l}\text { AS-VENEZIA ASSORTED TIN KCL } \\
1 / 12 / 250 \mathrm{~g}-\text { BUV01 }\end{array}$ & 7 & 5 & 2 \\
\hline 5 & $20 / 010100101 \mathrm{Z}$ & $\begin{array}{l}\text { GOOD TIME CLASSIC } 1 / 48 / 72 \mathrm{~g}- \\
\text { MGC93 }\end{array}$ & 1 & 1 & 2 \\
\hline
\end{tabular}

Tabel 7. Perangkingan perbandingan antara Troughput dan Space Requirement divisi P\&G

\begin{tabular}{|r|l|r|r|}
\hline No & Merek & \multicolumn{1}{|c|}{ TS/S } & Rangking \\
\hline 1 & AMBIPUR & 30.04 & 10 \\
\hline 2 & DOWNY & 441.45 & 2 \\
\hline 3 & GILLETTE & 130.61 & 6 \\
\hline 4 & HEAD \& SHOULDERS & 199.10 & 3 \\
\hline 5 & HERBAL ESSENCES & 9.09 & 12 \\
\hline
\end{tabular}

Tabel 8. Perangkingan perbandingan antara Troughput dan Space Requirement Arnot

\begin{tabular}{|r|l|r|r|}
\hline No & Nama barang & \multicolumn{1}{|c|}{ TS/S } & Rangking \\
\hline 1 & GOOD TIME & 61 & 1 \\
\hline 2 & NYAM NYAM & 51 & 2 \\
\hline 3 & TIM TAM & 48 & 3 \\
\hline 4 & VENEZIA & 7 & 4 \\
\hline
\end{tabular}

\section{Perbandingan Throughput dan Space Requirement}

Dari tabel sebelumnya sudah di dapatkan nilai dari Troughput dan Space Requirement, maka tinggal menghitung perbandingan antara kedua metode tersebut yakni Troughput dan Space Requirement.
Dalam peletakan produk di dalam gudang akan di sesuaikan dengan perbandingan antara Troughput dan Space Requirement dimana yang paling besar akan di taruh di tempat yangpaling dekta depan I/O sehinggadapat meminimalisir jarak tempuh dari barang tersebut. Berikut rangking dari setiap produk. Berikut tabel perbandingannya.

Tabel 9. Jarak Perjalanan Tiap Blok ke I/O point

\begin{tabular}{|r|r|r|r|r|r|r|r|}
\hline \multicolumn{4}{|c|}{ Lorong pertama } & \multicolumn{4}{c|}{ Lorong Kedua } \\
\hline $\begin{array}{r}\text { NO. } \\
\text { PALLET }\end{array}$ & $\begin{array}{c}\text { JARAK } \\
(\mathrm{M})\end{array}$ & $\begin{array}{c}\text { NO. } \\
\text { PALLET }\end{array}$ & $\begin{array}{c}\text { JARAK } \\
(\mathrm{M})\end{array}$ & $\begin{array}{c}\text { NO. } \\
\text { PALLET }\end{array}$ & $\begin{array}{c}\text { JARAK } \\
(\mathrm{M})\end{array}$ & $\begin{array}{c}\text { NO. } \\
\text { PALLET }\end{array}$ & $\begin{array}{c}\text { JARAK } \\
(\mathrm{M})\end{array}$ \\
\hline A1 & 14 & A27 & 17 & A53 & 17 & A79 & 20 \\
\hline A2 & 15.5 & A28 & 18.5 & A54 & 18.5 & A80 & 21.5 \\
\hline A3 & 17 & A29 & 20 & A55 & 20 & A81 & 23 \\
\hline A4 & 18.5 & A30 & 21.5 & A56 & 21.5 & A82 & 24.5 \\
\hline A5 & 20 & A31 & 23 & A57 & 23 & A83 & 26 \\
\hline A6 & 21.5 & A32 & 24.5 & A58 & 24.5 & A84 & 27.5 \\
\hline A7 & 23 & A33 & 26 & A59 & 26 & A85 & 29 \\
\hline A8 & 24.5 & A34 & 27.5 & A60 & 27.5 & A86 & 30.5 \\
\hline
\end{tabular}


Saddam Husin/ JISO, Vol. 3. No.1, Juni 2020,

Tabel 10. Posisi Produk Pada Penempatan Awal

\begin{tabular}{|c|c|c|c|c|c|c|c|c|c|c|c|}
\hline No & Jarak & Kode & $S$ & $\mathrm{~T} / \mathrm{S}$ & $\begin{array}{c}\text { Jarak } \\
\text { Tempuh }\end{array}$ & No & Jarak & Kode & $\mathrm{S}$ & $\mathrm{T} / \mathrm{S}$ & $\begin{array}{c}\text { Jarak } \\
\text { Tempuh }\end{array}$ \\
\hline \multirow{5}{*}{$\mathrm{A} 1$} & 14 & $\begin{array}{l}01 / 31602711 \\
0 \mathrm{E}\end{array}$ & 1 & 2 & 28 & \multirow{5}{*}{$\mathrm{A} 27$} & 17 & $01 / 244524603 \mathrm{E}$ & 1 & 2 & 28 \\
\hline & 14 & $\begin{array}{l}01 / 31602711 \\
2 \mathrm{D}\end{array}$ & 1 & 2 & 35 & & 17 & $01 / 244521108 \mathrm{~F}$ & 1 & 2 & 35 \\
\hline & 14 & $\begin{array}{l}01 / 31602711 \\
0 \mathrm{~L}\end{array}$ & 1 & 1 & 58 & & 17 & $01 / 244521108 \mathrm{G}$ & 1 & 3 & 58 \\
\hline & 14 & $\begin{array}{l}01 / 31602711 \\
2 \mathrm{~K}\end{array}$ & 1 & 1 & 50 & & 17 & $01 / 244521108 \mathrm{E}$ & 1 & 3 & 50 \\
\hline & 14 & $\begin{array}{l}01 / 31602711 \\
0 \mathrm{H}\end{array}$ & 1 & 2 & 84 & & 17 & $01 / 2445211050$ & 1 & 5 & 84 \\
\hline \multirow{5}{*}{$\mathrm{A} 2$} & 16 & $\begin{array}{l}01 / 31602711 \\
2 \mathrm{G}\end{array}$ & 1 & 2 & 75 & \multirow{5}{*}{ A28 } & 19 & $01 / 244521104 \mathrm{~T}$ & 1 & 4 & 75 \\
\hline & 16 & $\begin{array}{l}\text { 01/31602711 } \\
0 \mathrm{G}\end{array}$ & 1 & 2 & 57 & & 19 & $01 / 244521103 \mathrm{U}$ & 1 & 3 & 57 \\
\hline & 16 & $\begin{array}{l}01 / 31602711 \\
2 \mathrm{~F}\end{array}$ & 1 & 2 & 20 & & 19 & $01 / 244521108 \mathrm{D}$ & 1 & 1 & 20 \\
\hline & 16 & $\begin{array}{l}01 / 31602711 \\
1 \mathrm{~F}\end{array}$ & 1 & 1 & 2 & & 19 & $01 / 244521105 \mathrm{~N}$ & 1 & 0 & 2 \\
\hline & 16 & $\begin{array}{l}01 / 31602711 \\
1 \mathrm{~B}\end{array}$ & 1 & 0 & 4 & & 19 & $01 / 244524603 \mathrm{~A}$ & 1 & 0 & 4 \\
\hline
\end{tabular}

\section{Perhitungan Jarak Tiap Blok ke I/O}

Untuk memperhitungkan jarak perjalan setiap pallet atau slot ke I/O point dilakukan perhitungkan di setiap perjalanannya dengan mengukur jarak setiap blok yang ada. Dengan mengukur semua jarak tiap blok makan akan di ketahui seberapa besar atau jauh jarak tempuh tiap blok sehingga dapat diperhitungkan produk mana saja yang akan ditempatkan di tempat yang jauh dari titik I/O dan mana saja produk yang di tempatkan yang jaraknya dekat dengan titik I/O.

\section{Perhitungan Jarak Tempuh Total}

Dalam kasus ini di perlukan perbandingan jarak antara jarak pada kondisi existing dan konsisi usulan di mana dengan adanya jarak tersebut akan di ketahui seberapa efisien jarak yang di tempuh setiap produk.

\section{Perhitungan Kondisi Eksisting}

Pada keadaan sebenarnya dalam penempatan barang jadi tidak ada aturan yang jelas atau aturan yang baku dalam menempatkanya.

\section{Perbaikan Usulan Perbaikan}

Dalam penenmpatan usulan perbaikan ini di tempatkan berdasarkan perhitungan $\mathrm{T} / \mathrm{S}$ dimana nilai tertinggi akan di tempatkan di daerah yang terdekat dengan I/O point. Sehingga dalam melakukan penempatan produk tersebut harus di lakukan perangkingan atas dasar T/S tersebut.

\section{Perbandingan Jarak Tempuh Layout exsisting dengan Layout Usulan}

Setelah di lakukan perhitungan jarak tempuh awal dan jarak tempuh usulan perbaikan maka dapat di peroleh perbandingan untuk mengetahui seberapa besar perbandingan atau selisih jarak antara layout awal dan layout usulan perbaikan.

Tabel 11. Posisi Produk Pada Penempatan Usulan

\begin{tabular}{|c|c|c|c|c|c|c|c|c|c|c|c|}
\hline No & Jarak & Kode & S & $\mathrm{T} / \mathrm{S}$ & $\begin{array}{c}\text { Jarak } \\
\text { Tempuh }\end{array}$ & No & Jarak & Kode & S & $\mathrm{T} / \mathrm{S}$ & $\begin{array}{c}\text { Jarak } \\
\text { Tempuh }\end{array}$ \\
\hline \multirow{5}{*}{$\mathrm{A} 1$} & 14 & $01 / 2451246020$ & \multirow{10}{*}{20} & \multirow{10}{*}{10} & \multirow{10}{*}{1481.6} & \multirow{5}{*}{ A27 } & 17 & $01 / 2451210020$ & 1 & 4 & 76.0 \\
\hline & 14 & $01 / 2451246020$ & & & & & 17 & $01 / 245121002 \mathrm{~T}$ & 1 & 2 & 34.2 \\
\hline & 14 & $01 / 2451246020$ & & & & & 17 & $01 / 245121002 Z$ & 1 & 3 & 42.6 \\
\hline & 14 & $01 / 2451246020$ & & & & & 17 & $01 / 245121003 \mathrm{~N}$ & 1 & 2 & 40.0 \\
\hline & 14 & $01 / 2451246020$ & & & & & 17 & $01 / 245121008 \mathrm{I}$ & 1 & 1 & 15.4 \\
\hline \multirow{5}{*}{$\mathrm{A} 2$} & 15.5 & $01 / 2451246020$ & & & & \multirow{5}{*}{ A28 } & 18.5 & $01 / 245124501 \mathrm{~V}$ & \multirow{5}{*}{15} & \multirow{5}{*}{5} & \multirow{5}{*}{436.9} \\
\hline & 15.5 & $01 / 2451246020$ & & & & & 18.5 & $01 / 245124501 \mathrm{~V}$ & & & \\
\hline & 15.5 & $01 / 2451246020$ & & & & & 18.5 & $01 / 245124501 \mathrm{~V}$ & & & \\
\hline & 15.5 & $01 / 2451246020$ & & & & & 18.5 & $01 / 245124501 \mathrm{~V}$ & & & \\
\hline & 15.5 & $01 / 2451246020$ & & & & & 18.5 & $01 / 245124501 \mathrm{~V}$ & & & \\
\hline
\end{tabular}


Saddam Husin/ JISO, Vol. 3. No.1, Juni 2020,

Tabel 12. Perbandingan Jarak Tempuh layout awal dan usulan perbaikan

\begin{tabular}{|c|c|c|c|}
\hline Layout & Jarak Total & Selisih Jarak & prosentase Selisih Jarak \\
\hline Eksisting & $420,424.00$ & - & \\
\hline Usulan & $290,697.00$ & $129,727.00$ & $30.86 \%$ \\
\hline
\end{tabular}

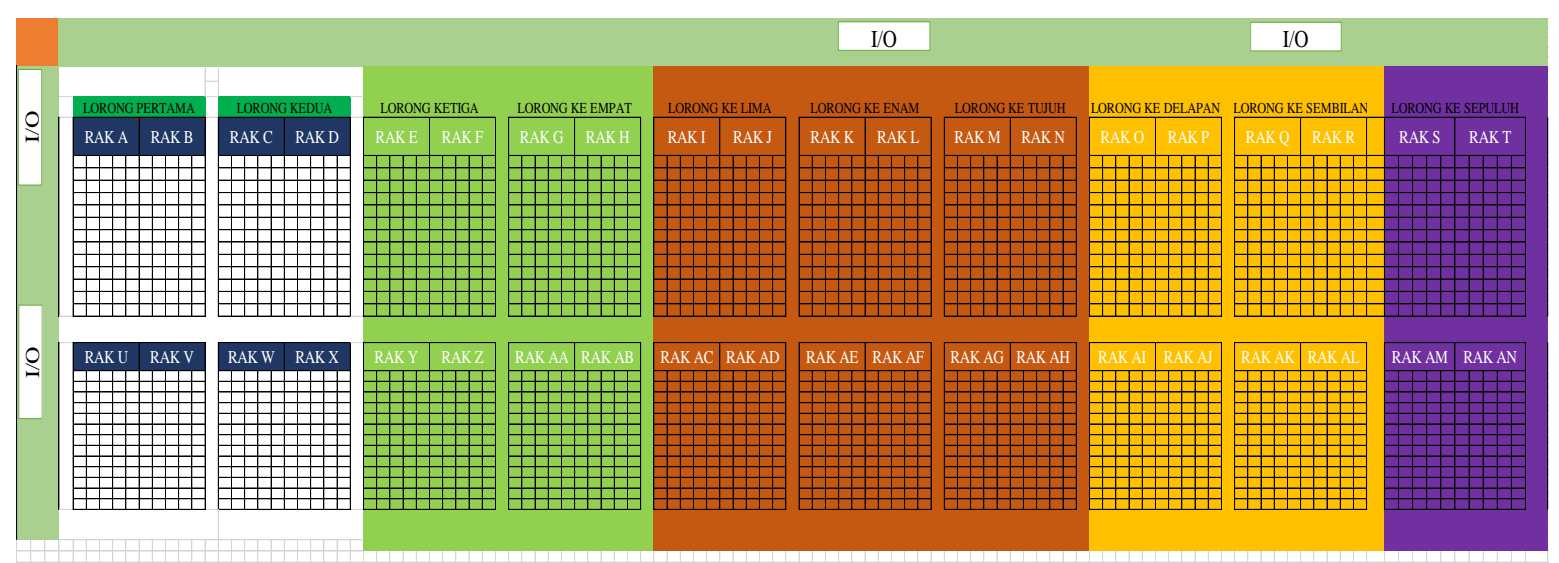

Gambar 2. Layout eksisting

\section{Keterangan :}

Putih : Aktivitas rendah ( $P \& G)$

Hijau : Aktivitas sedang ( $P \& G)$

Merah : Aktivitas tinggi ( $P \& G$ )
Biru : Aktivitas tinggi (Arnot)

Kuning : Aktivitas sedang (Arnot)

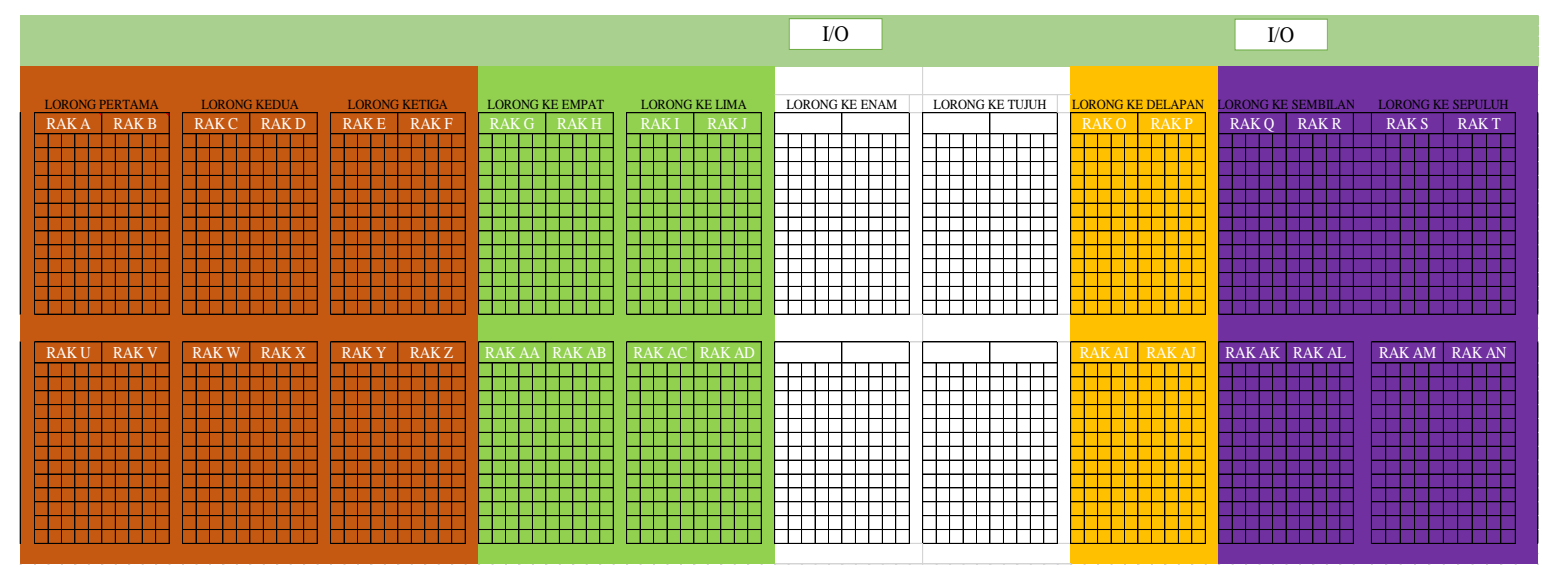

Gambar 3. Layout Usulan

\section{Keterangan :}

Putih : Aktivitas rendah ( P\&G)

Hijau : Aktivitas sedang ( $P \& G$ )

Merah : Aktivitas tinggi ( $P \& G$ )

Biru : Aktivitas tinggi (Arnot)

Kuning : Aktivitas sedang (Arnot)

\section{PENUTUP}

Dalam penelitian yang telah selesai dilakukan maka terdapat beberapa hasil yang telah di capai yakni total jarak tempuh menjadi semakin pendek yakni $290,697 \mathrm{~m}$ sedangkan jarak tempuh awal adalah $420,424 \mathrm{~m}$ sehingga mengalami penurunan $30,86 \%$ dan peletakan barang atau grouping semakin jelas karena adanya tempat yang tetap antar produk yang di simpan.

\section{DAFTAR PUSTAKA}

Efrataditama, A. V., \& Wigati, S. S. (2016). Perancangan Tata Letak Gudang Dengan Metode Dedicated Storage di Toko Listrik Anugrah Jaya.

Hadiguna, R. A., \& Setiawan, H. (2008). Tata Letak Pabrik. Yogyakarta: Andi. 
Melinda, I. D., Marpaung, S. T., \& Liquiddanu, E. (n.d.). Analisis Sistem Antrian Restoran Cepat Saji McDonald's dengan Menggunakan Simulasi Arena.

Permana, I. H. (2014). Relayout Tata Letak Gudang Produk Jadi Baja Tulangan Dengan Menggunakan Metode Dedicated Storage di PT. ABC. Cilegon: Universitas Sultan Ageng Tirtayasa.

Retnowati, D., \& Fudhla, A. F. (n.d.). RE-LAYOUT FASILITAS PRODUKSI INDUSTRI SHEET METAL WORKING BERBASIS JOB SHOP DENGAN PENDEKATAN LINEAR MIX INTEGER PROGRAMMING.
Rizal, M. H. (2015). Simulasi Proses Pemuatan Kapal Di Pelabuhan PT. Wina Gresik Dengan Tujuan Mengurangi Demurrage. Institut Teknologi Sepuluh Nopember.

Wardhani, I. K., Pratiwi, I. P., \& Liquiddanu, E. (n.d.). ANALISIS KINERJA ANTRIAN MENGGUNAKAN SOFTWARE ARENA 15.0. 